\title{
Adult Literacy Research: Opportunities and Challenges
}

\author{
John Comings, Director \\ Lisa Soricone, Research Associate \\ National Center for the Study of Adult Learning and Literacy \\ Harvard Graduate School of Education
}

\section{NCSALL Occasional Paper January 2007}

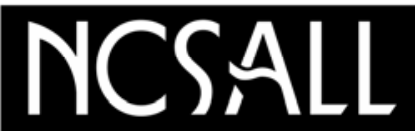

National Center for the Study of Adult Learning and Literacy

Harvard Graduate School of Education

101 Nichols House, Appian Way

Cambridge, MA 02138

\section{B. National Institute for Literacy}

\author{
National Institute for Literacy \\ 1775 I Street NW, Suite 730 \\ Washington, DC 20006
}

NCSALL Occasional Papers are funded by the Educational Research and Development Centers program, Award Number R309B960002, as administered by the Institute of Education Sciences (formerly Office of Educational Research and Improvement), U.S. Department of Education. The contents of this paper were developed using funds transferred from the National Institute for Literacy to the Institute of Education Sciences. The views expressed herein do not necessarily represent the positions or policies of the National Institute for Literacy, the Institute of Education Sciences, or the U.S. Department of Education. No official endorsement by the National Institute for Literacy, the Institute of Education Sciences, or the U.S. Department of Education of any product, commodity, service or enterprise mentioned in this publication is intended or should be inferred. 



\section{CONTENTS}

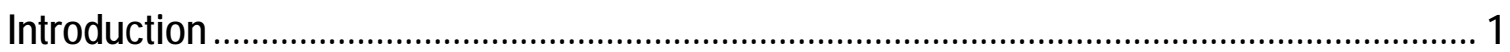

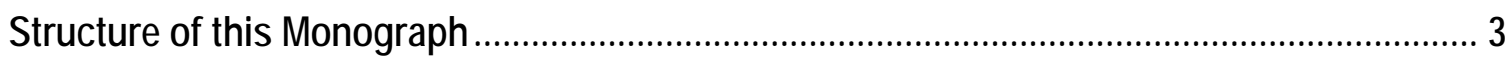

Opportunities Provided by Research in the Adult Literacy Field........................................ 5

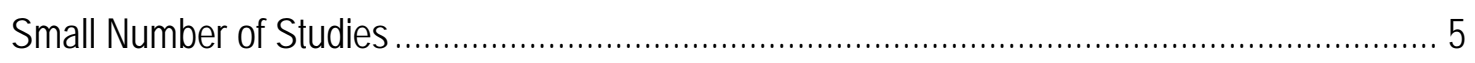

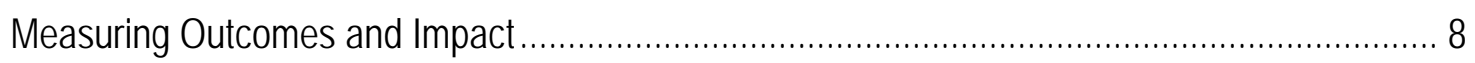

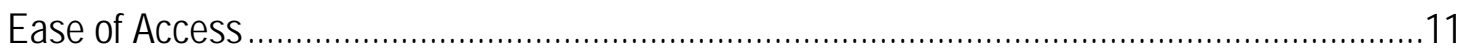

Challenges to Scientific Research in Adult Literacy............................................................13

Lack of Theory-based Models for Instruction and Services .................................................13

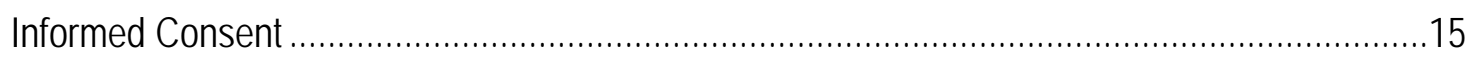

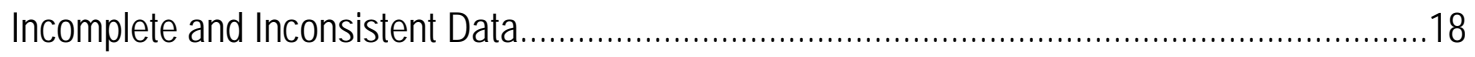

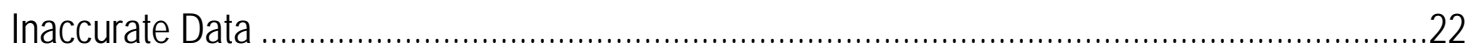

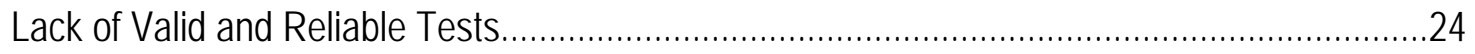

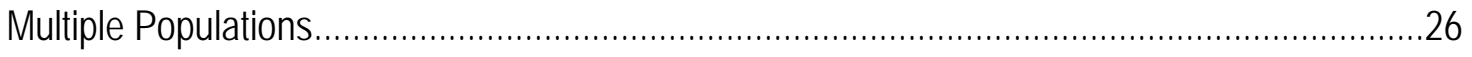

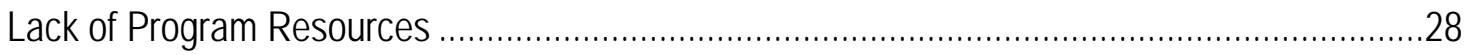

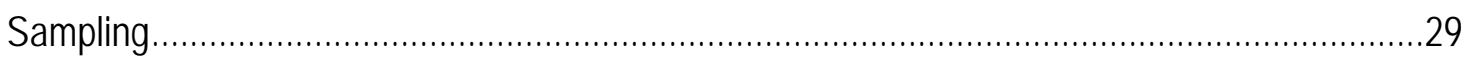

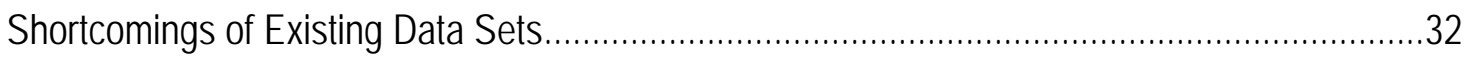

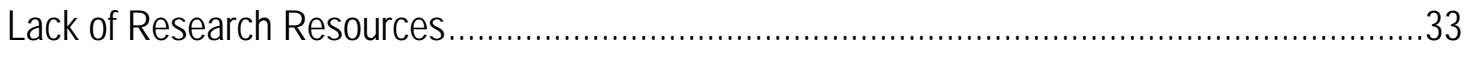

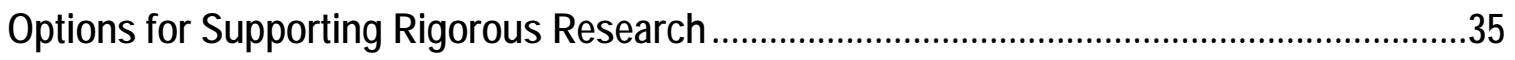

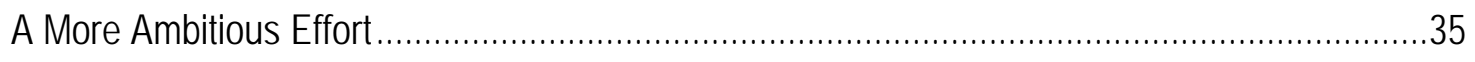

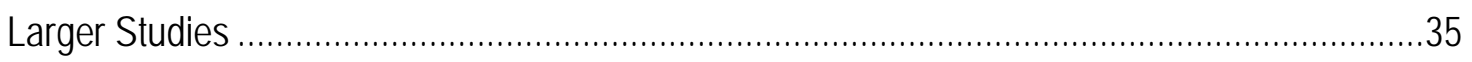

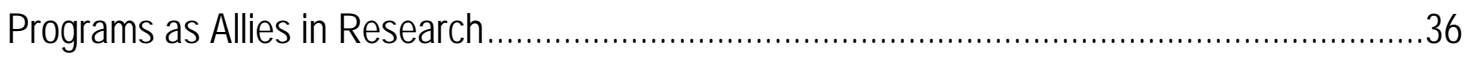

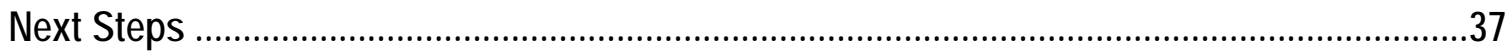

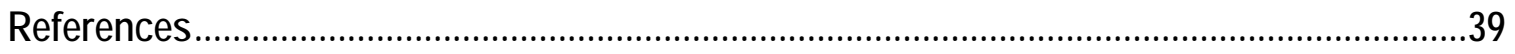

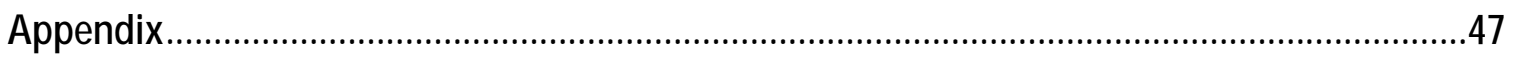

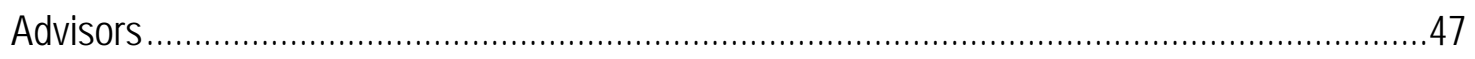

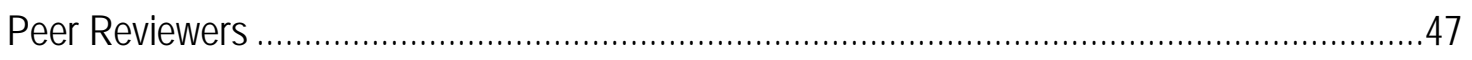

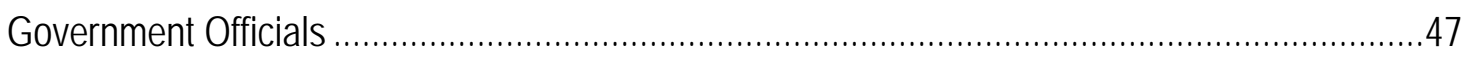





\section{INTRODUCTION}

Cognitive skills and educational credentials are strong predictors of success in the labor market (Kerckhoff, Raudenbush, \& Glennie, 2001). Unfortunately, a large proportion of the U. S. workforce does not have the skills and credentials required to secure and hold jobs that pay good wages and provide benefits (Comings, Reder, \& Sum, 2001). Since most workers are outside the K-12 system, investments in improving primary and secondary schools have little immediate impact on the skills and credentials of the workforce. An investment in K-12 education only leads to employment outcomes after 10 to 12 years, or even longer, while the impact for adult education could be immediate.

To address this need, the Workforce Investment Act's (WIA) Title II $^{1}$ supports educational services for adults; these services include adult literacy, adult basic education (ABE), family literacy, workplace literacy, adult English for speakers of other languages (ESOL), adult secondary education (ASE), and General Education Development (GED) programs. The benefits of successful participation in these programs accrue not only to our economy but to other aspects of our national life as well. The skills needed to succeed in the workforce are the same skills needed to succeed as parents and citizens. In addition, workers, parents and citizens must now continue learning throughout their lives. A strong foundation of basic skills and knowledge supports lifelong learning.

Adult literacy practitioners must make many decisions about how to design their programs to serve the goals of WIA. Practitioners usually base decisions about the design of program services on theories and approaches learned in training, the opinions of experienced practitioners, and personal experience gained through trial and error (Beder \& Medina, 2001; Smith, Hofer, Gillespie, Solomon, \& Rowe, 2003). Though these decisions often lead to programs that meet the accountability requirements of WIA, the practices employed by programs usually have not been rigorously evaluated.

WIA requires programs to base decisions about the design of programs on evidence from scientific research. The Department of Education defines scientific research as studies that are rigorous, systematic, objective, empirical, and peer reviewed and that rely on multiple measurements and observations, preferably through experimental or quasiexperimental methods. ${ }^{2}$ This evidence-based approach to making decisions is meant to insure that participants in adult literacy programs receive services that provide them with the best possible opportunity to gain the skills and credentials workers need to be successful in the labor market and in their roles as parents and citizens.

\footnotetext{
1 http://www.doleta.gov/usworkforce/wia/wialaw.txt

${ }^{2}$ http://www.northwestern.edu/ipr/events/lectures/DPPL-Whitehurst.pdf http://www.ed.gov/rschstat/research/pubs/ies.pdf http://www.ed.gov/nclb/methods/whatworks/eb/evidencebased.ppt http://www.ed.gov/rschstat/research/pubs/rigorousevid/index.html
} 
Unfortunately, the field of adult literacy only has a small foundation of scientific research. Beder (1999) reviewed 115 studies of program outcomes and impact in the field and found that only 23 met minimum standards for analysis. Once his review was complete, he concluded that even these 23 studies had flaws that significantly compromised the validity and usefulness of the findings. Kruidenier (2002) identified only 70 adult reading research studies that met the standards of scientific research. Comings, Soricone, and Santos (2006) reviewed the literature on advice for the design of services (including such factors as management, intake, orientation, support services, learning resources, and reengagement of dropouts, but excluding instruction of specific content such as reading, writing, or math) and found that little scientific research conducted in adult literacy programs supported the advice. All three reviews acknowledge that the weakness of the research base is due, in part, to challenges to obtaining meaningful results from scientific research that plague studies in the adult literacy field.

This paper has two goals that support the building of a stronger research base for the adult literacy field. The first goal is to interest researchers in pursuing rigorous scientific research in this field. Despite the many challenges to research, this field offers researchers some opportunities to have a positive impact on education, increase the research base, and advance their careers. The second goal is to identify these challenges and approaches to overcoming them so that future research could design more successful studies. Addressing these challenges to research is a critical step toward building a larger and stronger foundation of evidence to support practitioner decisions. 


\section{STRUCTURE OF THIS MONOGRAPH}

This monograph looks first at opportunities provided by research in the adult literacy field and then identifies challenges to scientific research and suggests ways to address these challenges so that better evidence can be generated in the future. The target group for this monograph includes present and prospective researchers but also policymakers and administrators who seek a better understanding of research in this field.

Researchers in this field have discussed the challenges to rigorous research for decades, usually in relation to the problems they faced in individual studies. This monograph looks across studies to identify the challenges and suggest ways to overcome them. Though this monograph provides advice on how to overcome the challenges to scientific research in this field, it also serves as a device for focusing a discussion that could lead to better advice. For both the challenges to and the opportunities of research in this field, the monograph identifies studies that provide examples, and readers who are interested in pursuing research in this field could follow up on these examples by reading the original reports of this research.

The preparation of this monograph began with the drafting of a discussion paper that summarized insights from published sources. That paper was discussed in a two-day workshop with a group of advisors, all of whom have been engaged in scientific research in this field and have reviewed the existing literature used by practitioners as sources of advice. The insights from that meeting formed the basis for a rough draft of this monograph, which was reviewed by members of that group and two researchers who were not able to attend the workshop. The suggestions from that review were incorporated in a first draft. The first draft was peer reviewed by scholars who have been working on the development of evidence-based practice in adult literacy, and their suggestions were included in this final version. The members of the group of advisors and the two researchers also commented on the first draft, and some but not all of their comments were incorporated into this final version. Three Department of Education officials provided comments and suggestions at several points during the preparation of this monograph. A list of the people who provided input into this paper is available in the Appendix at the end of this monograph. 



\section{OPPORTUNITIES PROVIDED BY RESEARCH IN THE ADULT LITERACY FIELD}

Research in adult literacy programs faces many of the same challenges as research in K12 schools, but some aspects of the adult literacy field are more advantageous to research than in the K-12 field and some are less advantageous. A discussion of the positive aspects of undertaking studies in the adult literacy field might encourage scholars to tackle its challenges. The three positive aspects described here are: (1) the small number of studies that both address important questions and apply rigorous scientific methods, (2) the possibility of measuring impact on several important adult roles, and (3) the ease of access to adult populations.

\section{Small Number of Studies}

Beder (1999), Kruidenier (2002), and Comings, et al. (2006) found that the field of adult literacy research has only a small number of studies that meet the criteria for scientific research. This is a problem for the field, but it could be an opportunity for researchers, particularly those who are at early stages in their careers. Since the field still has a wide array of basic questions to answer, adult literacy research offers scholars an opportunity to build part of the foundation for the field by answering questions that may have a significant impact on policy and practice. Researchers who are at early stages in their careers could establish a program of research that might continue for their whole career. In addition, research in adult literacy has the promise of having a positive impact on the lives of millions of adults.

These basic questions fall into domains that include descriptions of the population that needs services, approaches to instruction that work well with this population, approaches to the delivery of services that allow adults to participate in learning with sufficient intensity, duration, and engagement to make meaningful progress, and ways to measure the learning gains and life impacts of participation in programs. A review of the adult literacy literature on any of these domains quickly leads to many specific questions that have yet to be answered. Examples of specific questions that are of interest to practitioners and policymakers include how to help adults successfully transition from adult literacy programs into postsecondary education, how best to tailor instruction to adults at different literacy levels, and how to measure numeracy outcomes.

Some of these basic questions have been answered in the K-12 literature, and that literature provides a basis on which to build an adult literacy study. For example, in her analysis of the role of vocabulary instruction in adult basic education, Curtis (2006) points out that, despite the fact that vocabulary has long been recognized as a key factor in reading comprehension and as a significant variable in minority language learners' reading success in the $\mathrm{K}-12$ literature, few studies have focused specifically on 
vocabulary acquisition and instruction for adult learners. She outlines several hypotheses about the connection between vocabulary and reading comprehension developed through research on $\mathrm{K}-12$ students and recommends that the relevance of these hypotheses to adult learners be explored through future research. Similarly, Sawyer and Joyce (2006) report that the area of spelling is one in which little research has focused specifically on adult learners, although research has been conducted on school-age learners and some research has been done with sub-groups of adults, including those with learning disabilities and hearing impairments, as well as those enrolled in ESOL classes. The authors point to the need for future longitudinal studies of spelling development among adult students and experimental studies to assess the effectiveness of instructional methods for adults of varied literacy levels.

While such bodies of research provide a foundation for studies in adult literacy, so do existing data sets. Though many national data sets are not appropriate for adult literacy research, some data sets (such as those developed by the National Center for Educational Statistics [NCES], the Division of Adult Education and Literacy, and the GED Testing Service) do provide opportunities to explore questions of interest to the adult literacy field. In addition, many states now have effective student data systems that could be sources for secondary analysis. Since these data have already been collected and put in a form ready for analysis, studies with them are easily done without significant financial support. Moreover, the sample sizes available for research far exceed those that most scholars could collect without the investment of substantial resources.

These data sets have been the source of scientific research in the adult literacy field published over the last decade. For example, Hollenbeck (1996) used data from the National Household Education Survey and the Current Population Survey of 1991 to examine the benefits and costs of workplace literacy training. Murnane, Willett and Boudett (1995) employed data from the National Longitudinal Survey of Youth (NLSY) to determine whether the earnings and employment trajectories of male dropouts are affected by acquisition of a GED. In a later study (1997), the same authors used the NLSY data set to examine how dropouts' acquisition of a GED affects the probability of obtaining training, participating in postsecondary education, or joining the military services. Murnane, Willett, and Tyler (1999) used data from the High School and Beyond (HS\&B) data set to explore whether the labor market benefits of a GED are different for dropouts who leave school with very weak cognitive skills, compared with those for dropouts who leave with stronger cognitive skills. HS\&B data also served as the basis for a 2003 study by Tyler, Murnane, and Willett that examined the labor market value of the GED credential for female dropouts.

Soricone (2000) used data from the National Education Longitudinal Study (NELS) to investigate when dropouts are most likely to obtain a GED and whether dropouts who leave school with more years of schooling and higher cognitive skills are more likely to obtain their GED earlier. GED records from Florida and Texas served as 
the basis for Tyler, Murnane and Willett's 2004 analysis of GED re-testing regulations and passing score requirements. Uvin (2001) used data from the National Household Education Surveys of 1995 and 1999 (NHES: 95 and NHES: 99) to gain insight into the nature of participation in adult ESOL classes. In this study, Uvin explored whether knowledge of, perceived benefits from, and access to adult ESOL courses predicted whether non-native English speakers participated in ESOL classes and, among immigrant adults, whether Black, Hispanic, Asian, and other adults of color were less likely to participate in ESOL courses than White adults.

Other studies have employed unique data sets that have combined information from previously existing state-level data sets. In a 1998 study, Tyler, Murnane and Willett used a unique merged data set to estimate the impact of the GED on young dropouts' earnings. The data set contained the GED test scores (from the GED Testing Service) and earnings (from the Social Security Administration) of a sample of dropouts aged 16-21 who attempted the GED in 1990. This study eliminated the potential for selectivity bias arising from the motivation to take the test among individuals since all subjects had similar motivation to pursue the GED credential (therefore dropouts' earnings could not be attributed to differing levels of motivation). The study involved a series of "natural experiments" that arose because of different standards for passing the GED tests across states. Thus, the authors were able to compare the earnings of 80,000 dropouts who had similar skill and motivation levels but differed in whether or not they had a GED, because of differential state passing score requirements. This allowed the authors to focus on the labor market signaling effect of the GED credential itself.

In a 2004 study, Tyler and Kling explored the impact of earning a GED while in prison on the post-release earning of criminal justice offenders. The study was based on a unique data set constructed for the project by drawing on data from the Florida Department of Corrections, the Florida Department of Law Enforcement, and the Florida Education and Training Placement Information Program. The master data set contained basic demographic, criminal justice, and test score information, as well as post-release quarterly earnings (1994-2000) for males who had been incarcerated in Florida state prisons.

Using a unique data set that combined data from Florida's GED and Unemployment Insurance administrative records, Tyler (2004) conducted a series of studies on the value of the GED to dropouts who pursue the credential. Using a subset of the Florida data set used by Tyler, Soricone (2003) examined the relationship between basic skills and the earnings and employment outcomes of Spanish-speaking GED recipients. Uvin (2003) used administrative data sets from Massachusetts for a study of the employment and earnings trajectories of limited English-proficient workers experiencing job displacement. Data for the study were drawn from the Massachusetts Job Training Partnership Act management information system and the Unemployment Insurance earnings database of the Massachusetts Department of Revenue. 
Since, compared to the K-12 field, little scientific research on adult literacy has been published, researchers have an opportunity to address fundamental questions in this field by building on existing $\mathrm{K}-12$ research, which provides researchers with opportunities to propose studies that employ accepted theory and draw from tested methodologies. Some of these questions can be answered with existing data sets that have not been used for adult literacy research, providing researchers with opportunities to undertake studies without the need for original data collection.

\section{Measuring Outcomes and Impact}

Most educational research is focused directly or indirectly on instructional outcomes, such as higher test scores or greater high school completion rates. However, education also has an impact on outcomes valued by other fields. Investments in education can have an impact on such things as the economy, tax revenues, health indicators, and crime rates, for example. Funding sources interested in those types of impact may be interested in funding adult literacy research, and journals in these fields might be interested in publishing articles that explore impact from participation in adult literacy programs.

Comings et al. (2001) identify several types of hypothesized positive impact of successful participation in adult literacy services, including increased income and labor market participation, improved school performance of participants' children, and greater civic participation. These hypotheses are based on correlations between the skills and knowledge taught in adult literacy programs (such as reading) and indicators of these types of positive impact. These hypotheses assume that higher skills acquired as an adult have the same impact as skills acquired while in the $\mathrm{K}-12$ system. A small body of experimental studies (Hamilton, 2002 and Tyler, 2005, for example) supports some of these hypotheses. These types of impact are valued by policymakers and are the subject of research in both education and other fields.

These types of impact also accrue from investment in the $\mathrm{K}-12$ and postsecondary education systems (Behrman \& Stacey, 1997). However, the investment that begins when a child enters kindergarten and ends with graduation from high school or college does not begin to demonstrate impact until this long process is complete and students become workers, parents, and active citizens. Since adult participants are usually workers, parents, and citizens when they begin participation, investment in successful adult literacy programs could lead to impact immediately or within a few years.

In addition, some adult literacy programs focus their curriculum on specific adult roles. For example, family literacy programs are meant to have a direct impact on the school performance of participants' children, and workplace literacy programs are meant to have a direct impact on employment and income. General programs sometimes focus 
part of their curriculum on health, the environment, or community involvement. These program interventions might lead to immediate impact.

Bingman, Ebert, and Smith (1999) reported on a longitudinal study of adult literacy participants in Tennessee from 1991 to 1995. The study set out to determine the impact of participation in adult literacy programs on the lives of adult students. The study focused on changes in the domains of work, family, and community after the individuals enrolled in literacy programs. Interviews with 199 individuals conducted one year after enrollment revealed positive change in the areas of employment, community involvement, and children's education.

Focusing on the adult role of parent, Waterman (2006) analyzed data from an experimental study that explored the impact of an intervention designed to promote parental involvement in children's education through adult ESOL classes. The intervention was implemented over a six-month period after which outcomes were assessed. The study found that mothers in the treatment group experienced greater gains in both ESOL skill levels and parental involvement scores than mothers in the control group. Differences between the results of the two groups were statistically significant. Waterman's study represents an instance where the immediate impact of adult literacy education was twofold, appearing within and beyond the classroom.

Using data from the National Household Education Survey (NHES) and the Current Population Survey (CPS), Hollenbeck (1996) explored the economic impact of workplace literacy programs. He found that, even when controlling for industry and occupation, participation in workplace literacy was associated with an $8 \%$ to $13 \%$ increase in earnings.

Economic data is often available for multiple years, allowing for judging both immediate and long-term impact. For example, in a study of incarcerated dropouts, Tyler and Kling (2004) found that, among racial and ethnic minorities, positive effects of the GED observed during the first year of post-release disappeared after two years. Among white dropouts, no effects of the GED were observed across the three post-release years included in the study. In a study of Florida GED test takers, Tyler (2002) tracked dropouts over three years following GED examination attempts and found that those who scored a standard deviation higher on the GED math exam had earnings that were $6.5 \%$ higher than those of dropouts with lower GED math scores.

Several studies focus on a five-year period to observe economic impact. Tyler, Murnane and Willett (2000), examined the skills-earnings relationship for dropouts in New York and Florida five years after they had attempted the GED tests. The authors found large earnings returns to cognitive skills for both males and females, regardless of whether or not dropouts had successfully obtained the GED. Tyler et al. (1998) examined 
the economic impact of GED acquisition across a national sample of dropouts five years after receipt of the credential. The authors found that GED acquisition increased the earnings of white dropouts; however, no effects were observed for the earnings of minority dropouts.

Similarly, the National Evaluation of Welfare-to-Work Strategies (NEWWS) tracked participants over a five-year follow-up period (Hamilton, 2002). The study consisted of a randomized experiment that compared the outcomes of over 40,000 welfare recipients (predominantly single mothers) who participated in welfare-to-work programs with those who did not. Among the study findings, researchers noted that all 11 of the NEWWS programs “increased single parents' employment and earnings and decreased their welfare receipt and payments relative to the levels found in the programs' absence" (Hamilton, 2002, p. 23). Despite the fact that programs helped participants become more self-sufficient, their total income (from work and benefits) did not increase, since, as work income increased, benefits decreased.

Adult literacy programs offer an opportunity to educational researchers to partner with scholars from other fields and draw from research funding resources in those fields, when measuring impact. For example, research in recent years has established strong links between literacy and health outcomes. In a review of research, Rudd, Moeykens, and Colton (2000) report that low literacy levels have been associated with poor health status (Weiss, Hart, McGee, \& D’Estelle, 1992, cited in Rudd et al., 2000), higher reported history of heart disease and diabetes (TenHave et al., 1997, cited in Rudd et al., 2000), reduced use of health services (Baker, Parker, Williams, Clark, \& Nurss, 1997, cited in Rudd et al., 2000), reduced use of mammography screening leading to later stage diagnosis of breast cancer (Davis, et al. 1996, cited in Rudd et al., 2000), and less of the knowledge required for self-management of chronic diseases (Williams, Baker, Parker, \& Nurss, 1998, cited in Rudd et al., 2000).

While little health literacy research has been conducted specifically focused on students in adult literacy classes, the possibility of targeting health literacy research on these students offers great potential. As Rudd et al. (2000) suggest, adult literacy programs "provide ready access to populations with low functional health literacy, and both teachers and students from these programs can be engaged in the strategic development work (formulating and testing strategies) that must take place to address fully the health-related needs of this target group” (p. 184). Thus, involving students in adult literacy classes in research on improving strategies for working with less literate patients could provide important insights with implications for the health outcomes of adult literacy students and other adults who face similar health literacy challenges. This is an area of research in which public health scholars and funding agencies have already shown an interest. 
Drawing support from the national interest in welfare reform, research conducted for the NEWWS provides useful insights into the effectiveness of different program approaches to serving welfare clients. The study showed that "employment-focused programs generally had larger effects on employment and earnings than did educationfocused programs” (Hamilton, 2002, p. 28). However, the most effective program was one that employed a mixed strategy, which outperformed other programs in terms of the size and consistency of its earnings gains, as well as increases in the stability of employment and earnings growth. This program's success suggests several key features of effective programs: "an employment focus, the use of both job search and short-term education or training, and an emphasis on holding out for a good job” (Hamilton, 2002, p. 36).

Many of the fields that could be linked to adult literacy have much greater research funding than does the adult literacy field. In addition to expanding the support available for research, partnerships across sectors open up a wider range of publication opportunities. Most of these relationships have not yet been formed, and those that have, between adult literacy and public health and labor economics, for example, are recent. However, these relationships offer great promise for both sides of these possible partnerships.

\section{Ease of Access}

Researchers working in $\mathrm{K}-12$ schools face challenges in obtaining access to research subjects because almost all of those subjects are under the age of 18. Parents of these students, or school administrators acting on their behalf, must give consent to children's participation in studies. Often, decisions to participate must involve several levels of an educational bureaucracy. For example, to conduct a study of social class influences on the adjustment to middle school in a rural northeastern school district, San Antonio (2001) was required to obtain the consent of the district superintendent. Even after responding to the superintendent's initial critiques of her research design, San Antonio found that her request for access to students was refused. More than one year after her initial request, after redesigning her study as a community-based, rather than a schoolbased one - and after school administrator and school board approval—San Antonio was finally granted the opportunity to work directly with middle school students in two district schools in order to carry out her research. Had it not been for her experience and community contacts within the district, she would likely have had to abandon her study.

In contrast, adult students can give their direct consent to participate in a research project. In addition, most adult students are participating in programs of their own volition, while children are required by law or by their parents to attend school. Adult students can make a decision about missing class time to participate in a study, while that decision must be made by parents and school administrators for children. Adult literacy researchers who reviewed this paper expressed that most programs were open to researchers studying their efforts. For some studies, this ease of access 
may be an advantage to undertaking research in the adult literacy programs as opposed to $\mathrm{K}-12$ schools.

Researchers interested in the K-12 system might find working with adult literacy students an easier way to explore some hypotheses. Younger students in adult literacy programs are close to the age of high school students. Often, these young students are in adult literacy programs because they were not successful in the $\mathrm{K}-12$ system. They may, therefore, be good subjects for studies that seek to help underperforming adolescents achieve in school. In program year 2003-2004, 372,591 (14\%) of WIA Title II students were aged 16-18, while 677,540 (25\%) were aged 19-24. Of these students, 37,917 (3\%) aged 16-18, and 230,522 (20\%) aged 19-24, were immigrants in ESOL classes (U.S. Department of Education, 2006). Because of the relative ease of involving them in research, young immigrant adults in these programs may be good subjects for studies that seek to help immigrant adolescents in school.

During the early stages of a research project, a study may be easier, quicker, or less expensive to undertake with young participants in adult literacy programs than with children in schools. Approaches to instruction could be developed and tested on a small scale with young adults and then tested later with high school adolescents once the pilot effort gave initial support to the efficacy of the approach. A research and development effort with young students in adult literacy programs, therefore, could identify interventions that would be highly likely to work with adolescents in high school. A study with 18- and 19-year-old adult literacy students might be easier and less expensive than one with 16- to 17-year olds in school, though the two groups would have to be similar in most other ways.

A NCSALL-supported study that will publish its results next year is an example of this opportunity. This experimental study is focused on adults whose reading ability falls in the range of grade level equivalent 5 to 8 . Some of the adults in this study are not much older than high school students, many of whom have similar reading scores. Over one third (35\%) of the study subjects are under the age of 22. The findings from this adult literacy study could inform a similar study with high school students, providing insight that would strengthen both the intervention and the research methodology. 


\section{CHALLENGES TO SCIENTIFIC RESEARCH IN ADULT LITERACY}

Once convinced that adult literacy offers opportunities for studies, a researcher must still overcome challenges to successful implementation of research. Two discussions of research in the adult literacy field have identified several challenges to rigorous research that may be greater than they are in K-12 schools (Beder, 1999; Greenberg, 2007). The group of advisors looked at this literature and drew on their own experience to identify several additional challenges to success in research in adult literacy programs. These challenges are described here and suggestions for overcoming them are provided. The challenges include: (1) lack of theory-based models for instruction and services, (2) informed consent, (3) incomplete and inconsistent data, (4) inaccurate data, (5) lack of valid and reliable tests, (6) multiple populations, (7) lack of program resources, (8) sampling, (9) shortcomings of existing data sets, and (10) lack of research resources.

\section{Lack of Theory-based Models for Instruction and Services}

One theme that arose out of the discussion among the group of advisors was the lack of theory on which to develop models for instruction and services in this field. Adult literacy sometimes builds its models by drawing on theory for instruction from the K-12 system. For example, years of theory development in $\mathrm{K}-12$ reading instruction led to the testing of the components approach to teaching reading, which proved effective as a model for instruction for young children (Curtis, 1980, 1997; Read, 1988; Stanovich, 1986). Since then, additional research has been able to build on this foundation.

Adult education research is also building on this foundation. For example, Greenberg, Ehri, and Perin $(1997,2002)$ conducted research to explore the word-reading skills of low-literate adults. Their studies were based, in part, on theory developed with children and used comparisons with children to help elucidate adult learner reading and spelling processes. Alamprese, Tao, and Price (2003) investigated ABE instructors' use of $\mathrm{K}-12$, structured reading curricula with low-level adult students and found that the use of these curricula was associated with learners' development of their decoding skills. The National Institute for Literacy (NIFL) and the National Institute for Child Health and Human Development (NICHD) are funding research that tests the K-12 model for literacy instruction with adults.

Research in adult literacy also draws on general adult education theory, but most of this theory was developed through research on adults who have the skills and credentials that adult literacy students lack (Merriam, 2004). Research designs based on theory drawn from $\mathrm{K}-12$ education or adult education research might be appropriate for some adult students but not those with the lowest literacy skills who often have challenges to learning, such as learning disabilities or cognitive disabilities. For example, Strucker and Davidson (2003) found that the lowest-level adult literacy students had 
reading components profiles that looked like those of reading disabled $\mathrm{K}-12$ students. Outcomes for these students may be constrained by their disabilities and their previous difficulties in school. K-12 theory developed out of research with reading disabled K-12 students might be appropriate for designing adult education research, but theory developed out of research with average students might not.

In their study of 643 low-level adult literacy students, Alamprese et al. (2003) asked learners to indicate whether they currently have a learning problem or disability or if they had one as a child. The authors reported that $41 \%$ of subjects indicated that they currently have a problem, and $40 \%$ noted that they had a problem as a child. Learning problems were more common among native-born students than immigrants.

The lowest-level literacy students may benefit from the approaches used with learning disabled children, but this approach may bring benefit only to adult students who study for many hours each year. Adult students usually spend only a limited number of hours each year in programs, and they may need different outcome measures to identify benefit. In fact, Reder (in press) found that some participants in adult literacy programs do not improve their literacy skills but do make positive changes in their literacy practices. Changing the outcome measure from improvement in reading skills to ability to accomplish specific tasks might lead to intervention designs that produce more robust impact. For example, Silver-Pacuilla (in press) suggests that assistive technology might provide immediate impact (increased ability to accomplish reading and writing tasks), while also slowly improving literacy skills. For example, computer programs that assist reading with text-to-voice recognition and dictionaries could help students begin reading better and provide their teacher with information on specific vocabulary problems that could form the focus of instruction. An intervention that helps reading disabled adults use assistive technology to address their daily literacy needs, while still helping them improve their component skills, might be more productive.

$\mathrm{K}-12$ reading theory can provide the basis for further research on adult learners. However, $\mathrm{K}-12$ theory is being tested within the existing model for adult literacy programs. As do $\mathrm{K}-12$ schools, the existing model for literacy programs requires adults to attend classes at specific times and in specific places. This model also assumes that adults can spend hundreds or even thousands of hours in classes over several years, as do school children.

Findings from the longitudinal study of adult learners in Portland, Oregon (Reder, in press) suggests that adults employ episodes of program participation and selfstudy over years of engagement in learning to reach their educational goals. Many adults study on their own, stop studying, and then join a program only to stop again. They may repeat a version of this pattern over many years. This research suggests that services might be more effective if they supported connected episodes of program participation and self-study. 
Research that tests models of instruction may prove them effective with only those students who are able to participate in services designed on a school model. If that group represents a minority of the adult student population, then research may not find those models to be effective or find that they lead to only modest gains. However, in a program designed to accommodate connected episodes of program participation and selfstudy, the same instructional approaches may prove highly effective.

One option to address this challenge would be to divide the model for programs, for research purposes, into two parts:

1. Instruction of specific content (such as reading, writing, math, English, and preparation for the GED test). This could take the form of curriculum and materials that teachers and students use to improve skills and knowledge or expand practices.

2. Services to support instruction (such as recruitment, intake, orientation, persistence support, program management, intensity and duration of instruction, use of technology, and transition to postsecondary education or training). This could take the form of program structures and processes that enable students to participate in instruction with sufficient intensity, duration, and engagement to make meaningful progress.

The field could then adapt K-12 models for instruction and focus adult literacy research on effective models for services. Research, such as the Portland longitudinal study, could build theory on which models could be designed and tested. Once new models for services are developed and proven effective, research on improving instruction of specific content might be more productive.

The scholarly discourse that would have developed stronger theories has been constrained by a low level of research funding, a small number of academics committed to this field, and a limited number of journals focused on adult literacy. Given this situation, employing $\mathrm{K}-12$ and adult education theory is a reasonable approach to research design. However, the nature of adult literacy students and programs makes this adaptation problematic.

\section{Informed Consent}

Informed consent of subjects in a research study has always been important, but it is now an essential element of every study (Raich, Plomer, \& Coyne, 2001). Researchers must "describe the research process to potential human subjects, explain the potential benefits and risks...provide assurance that no benefits or standing will be lost by non-participants, and clarify that consent is voluntary and may be withdrawn by the participant at any time" (Ross, Sundberg, \& Flint, 1999, p. 2). Informed consent "generally implies that a person 
(1) has the capacity to consent, (2) has been informed of significant ramifications concerning the procedure, (3) has freely and without undue influence expressed consent, and (4) consent has been appropriately documented” (American Psychological Association, 1992, Section 4.02, ๆa). Seeking the consent of research participants allows them to be involved in the research process and encourages both a sense of ownership and an interest in the process of the research (Green, Duncan, Barnes, \& Oberklaid, 2003).

Greenberg (2007) identifies gaining truly informed consent, as opposed to gaining signatures on an informed consent form, as a challenge to research in the adult literacy field. The subjects in adult literacy studies usually have limited literacy skills or weak English language skills. This makes both oral and written approaches to informed consent difficult and sometimes impossible.

This is, of course, an ethical challenge to research, but it is also a practical challenge for two reasons. First, funding agencies and the institutional review boards (IRB) of research institutions are seeking greater assurance that subjects are giving truly informed consent (Raich et al., 2001; Green et al., 2003). The procedures set up by IRBs may assume English literacy skills greater than those of subjects in an adult literacy study. The inability to provide assurance of informed consent might cause delays in the approval of research projects and even jeopardize funding altogether. Second, potential subjects who do not understand the informed consent or find it difficult may be more likely to say no, lowering the percentage of subjects who have the lowest language or literacy skills in a study sample. This might jeopardize the generalizability of study findings to programs that serve the lowest-level students.

Focusing on the issue of informed consent among students and parents in Australia, Green et al. (2003) offer some recommendations for adapting research information to increase the likelihood of informed decisions about participation. These include expanding the number of comparisons, analogies, or examples, as well as using pictures, diagrams, or videos for explanations. In addition, they suggest a focus on plain language (using common everyday words rather than technical ones), minimizing the use of unnecessary information not related to main concepts, and employing direct, conversational writing. As the authors note, adopting such an approach can shorten the time between research proposal submission and approval and contributes to a positive change in meeting the information requirements of parents and young subjects.

Raich et al. (2001) suggest stronger action on the part of IRBs to encourage researchers to obtain truly informed consent. A process to do so should include "asking investigators to describe what they will say to subjects, how much time is provided for decision making and who specifically will obtain the consent” (p. 441). The authors also suggest that structured teaching, explicit categorization of information, and direct questioning lead to both higher comprehension and better recall among potential study subjects. 
In her recent study, Greenberg (2007) read the informed consent forms aloud for her subjects, but she points to her own previous research (Greenberg et al., 1997) that shows adults with low literacy skills also have low oral receptive vocabulary levels. Subjects may hear what they are consenting to but may not understand it. For example, Greenberg's university IRB required that informed consent forms and procedures inform subjects that data about them would be stored in password-locked computers. She felt the subjects in her research would not understand the concept of password-locked computers.

Many subjects in adult literacy research are immigrants who have low oral and literacy skills in English. This obviously complicates the informed consent process if researchers must provide oral procedures and written forms in several languages. The ESOL Lab School at Portland State University provides an example of a way to ensure that students are able to provide truly informed consent for participation in research.

One of the unique qualities of the Lab School is its use of "comprehensive recordings of classroom language” (Reder, 2005, p. 5). Recordings include what both teachers and students are doing and saying, especially to one another. In order to gather this essential data, the Lab School added informed consent procedures to the school's standard intake and orientation process. Prospective ESOL students in the Lab School were shown a video in their native language and given a tour of the Lab School classroom and recording facilities. Prospective students were then given the opportunity to sign an informed consent form in their native language, which granted researchers permission to use students' recorded voices and images. If at any time students were uncomfortable with their participation in the research, they were permitted to transfer to other sites within the overall program. Researchers found that very few students chose to leave (Reder, 2005).

Raich et al. (2001) support such use of audiovisual materials, which, as they point out, provide supplementary information, improve recall, and increase both the satisfaction and likelihood of study participation. However, even with a well-designed oral or video presentation, some indication from the subjects that they understand the decision they are making would ensure that the consent is truly informed (Titus \& Keane, 1996, cited in Raich et al. 2001; Williams, Rieckmann, \& Trenholme, 1977, cited in Rudd et al., 2000). That indication of understanding could come through a description by the subject of what it is they are consenting to do. Since a subject and a researcher may speak different languages, a translator may be necessary. This could be a costly and timeconsuming process; however, it may be the best means of ensuring that subjects fully understand the implications of participating in research.

Most adult literacy research is similar to $\mathrm{K}-12$ research in relation to the core objectives of informed consent. The point of informed consent is to provide sufficient information to potential subjects so that they understand what they will be participating in while empowering individuals to "enter into a voluntary revocable agreement to 
participate, pending actual experience once the research begins” (Ross et al., 1999, p. 171). A field-wide effort to develop basic informed consent media in multiple languages could help researchers to secure basic consent. Researchers in other fields, public health for example, have to address the problems of informed consent with low-literate and nonEnglish speaking adults, and the adult literacy field could draw on that experience. Researchers would then have to complete the process with only the specifics of their study.

\section{Incomplete and Inconsistent Data}

Beder (1999) and Greenberg (2007) identify incomplete and inconsistent data as a challenge to research in the adult literacy field. Some well-resourced studies are able to maintain their sample. For example, Alamprese et al. (2003) were able to maintain $70 \%$ of a sample of 920 learners over a nine-month period. However, adult literacy students are often not available for testing because of sporadic attendance and unannounced dropout. This leads to many subjects who have been given a pretest but who are not available for a posttest. Often, these dropouts cannot be contacted, and this leads to high levels of attrition from the study. The time spent in instruction between pretest and posttest is often different among individuals in a population of subjects as well, since attendance patterns are inconsistent. High attrition rates and inconsistencies in the amount of treatment can make findings useless or at least less useful.

This condition is the result of factors in the lives of program participants that lead to dropout and erratic attendance. Some programs address this condition by employing an open enrollment policy that allows participants to enter and leave services at any time. An adult education class, therefore, might have the same number of students at the end of a term as at the beginning, but they might be a widely or even completely different group of people. Even when programs employ managed enrollment, students are likely to drop out and to have different hours of engagement.

The problems caused by a small attrition rate or small differences in the intensity or duration of treatment can be addressed by employing statistical controls, after checking for differences between those who drop out of the study and those who do not. However, high rates of attrition are common, even in well-designed, randomized experiments in adult literacy research. For instance, a 1994 study of the adult literacy classes in a welfare-to-work program, which involved a sample of 1,115 clients who were randomized and followed up with appropriate data collection, experienced an attrition rate of 35\% (Martinson \& Friedlander, 1994, cited in Brooks, Torgerson, and Porthouse, 2003). As Brooks et al. (2003) point out, attrition rates of this magnitude can lead to a bias in results if the attrition is not random.

Some of the studies reviewed by Beder (1999) suffered from both high attrition rates and treatment issues. For example, the National Evaluation of Adult Education 
Programs (Young, Fleischman, Fitzgerald, \& Morgan, 1995) study began with pretests for 8,581 subjects but ended with only 1,919 posttested subjects, only a little above $22 \%$ retention. Due to a number of validity issues, including the fact that a group of ESOL students had more than 50 hours of instruction prior to taking a pretest, the final analysis of learning gains was conducted with a sample of only 614 subjects, roughly 3\%of the total potential test sample (Young, Fleischman, Fitzgerald, \& Morgan, 1994).

The Tennessee Longitudinal Study (Bingman et al., 1999) set out to understand how participation in literacy programs changes adults' quality of life and focused on adults with low levels of literacy skill. Data collected in the first year were to serve as a baseline for comparisons with subsequent years. During the first year, while researchers planned to interview 240 learners, only 133 qualified for the study. Longitudinal comparisons were to be made in the second year. However, attrition resulted in a sample of only 70 in the second year. In addition, the composition of the sample changed substantially with respect to geography, race, and employment status. Second-year data were to be collected one year after the initial data collection; however, in reality, followup data were collected between 12 and 20 months after the baseline data (Beder, 1999, p. 50). Because of such factors, as well as the withdrawal of funding needed to complete the study, the analysis that researchers were able to conduct and the inferences that could be drawn from the data were quite limited.

One option for keeping attrition rates to a minimum is to invest substantial resources for keeping participants connected to a study. Reder (2006) reports that the Portland longitudinal study maintained 93\% sample retention with approximately 1,000 high school dropouts over six years with significant effort and investment. When subjects were recruited, they were told that they were a source of information and expertise, rather than a population to be studied. This may have built a sense of obligation and commitment to the study. Subjects were also paid \$35 for the first wave of data, and that payment increased to $\$ 50$ for the fifth wave of data collection. This payment acted as an incentive for participation, but it also served as an acknowledgement of the important role the subjects were playing in the study. As they met with study participants, members of the research team worked to establish and maintain rapport, an element that has been important to their success in maintaining the sample (S. Reder, personal communication, June 8, 2006).

Researchers made multiple efforts to stay in touch with participants between data collection periods. This helped to maintain rapport and provided useful information, including specific contacts, for locating participants for the next wave of data collection. Staff called participants every three months between data collection waves and sent periodic postcards to "say hello" and stay informed of address changes. They also sent out a newsletter once a year. In addition, the study used a "variable incentive" (lottery) to encourage participants to stay in touch with researchers between waves of data collection. When there were two years between interviews, the research team held a raffle. In the 
newsletter, the team announced that individuals who provided up-to-date contact information by a certain date would be entered into a raffle in which the team gave away \$100 each to five people (C. Strawn, e-mail communication, June 20, 2006).

Substantial efforts were also made to keep in contact with subjects who were not immediately available for data collection. Participants voluntarily gave researchers contact information to use in the event that a participant could not be located. In some instances, staff was unable to locate contacts and so would make use of Web-based services to locate the missing participant. Participants gave permission for such a process, and it was made clear that if at any time participants were uncomfortable with such a search, they could pull out of the study. In cases where individuals had moved too far away for the team to collect data in person, the research team would undertake a phone interview and hire a local researcher to do the hands-on portion of data collection.

The Portland longitudinal study benefited from the hard work and significant investment in retaining the sample built into the study design. In addition, graduate students were well trained and highly committed to doing a good job. Much of the success in maintaining the sample is attributable to their efforts (S. Reder, personal communication, June 8, 2006).

Since the resources to maintain a large sample over time may not be available, some studies employ a limited time period for the data collection. Several studies have limited their collection time to four months but have been able to identify effects. Comings, Parrella, and Soricone (1999) explored persistence among 150 students in preGED classes in New England. Students were interviewed in order to understand the factors that promote and hinder their persistence. The first round of interviews took place between October and December. Four months after the first interview, researchers attempted to contact all study participants and successfully interviewed 79\% (119) of the original sample. Even with this short time period, the study was able to identify several factors that had statistically significant positive relationships to persistence: being age 30 and over; having teenage or adult children; having been schooled outside the U.S.; and stating a clearly defined goal at the beginning of the study.

In their study of mid-level readers, Strucker, Curtis, and Adams (in press) tested subjects at the beginning and end of a semester (after 30 hours of instruction) in order to observe changes in students' reading levels, based on four variations in approach to reading instruction. Subjects were also tested approximately one year later to see if gains were maintained. Of the 274 students pretested, 205 persisted in their classes long enough to be posttested at the end of the semester. Subjects are also undergoing follow-up testing one year later (J. Strucker, personal communication, December 6, 2006). 
In the What Works Study for Adult ESL Literacy Students, researchers assessed subjects at the start of instruction and at three- and nine-month intervals, regardless of whether or not individuals continued to attend ESL classes. Of the 495 students pretested, 356 (72\%) took the second assessment and 263 (53\%) took the third set of assessments (Condelli, 2002). Using a growth modeling approach, researchers found that three instructional strategies were related to growth in student literacy and language learning: "connection to the outside world, use of the student's native language for clarification in instruction, and varied practice and interaction” (p. 27).

Most studies address the problem of inconsistent time-on-task by collecting contact hours. Ranges can be quite wide, but statistical processes can account for these differences. In a study of adult learner persistence in library literacy programs, Comings, Cuban, Bos, and Porter (2003) report that learners averaged 57 total hours of participation over an 18-month period. Students ranged substantially in their participation, with 21\% having over 80 hours of activity and 24\% having 10 hours or less of participation. Monthly participation ranged from 3 hours or less to 13 hours or more. In the final report of the study (Porter, Cuban, \& Comings, 2005), researchers report that participation of a sample of the students ranged from 2 hours to 744 hours in tutoring, classes, or computer lab activities over a 14-month period. Ultimately, no significant relationship was observed between time spent in attendance at a literacy program and literacy achievement. Study authors concluded that most students are not persisting enough “to make meaningful gains on standardized tests” (Porter et al., 2005, p. 25).

A study by Comings, Sum, and Uvin (2000) explored the relationship between learning gains to hours of instruction over the course of a program year in Massachusetts. The range of hours of instruction varied from 10 to over 200 hours, with a median of 74 hours. In its descriptive data, the study revealed that "as students receive more hours of instruction, they are more likely to achieve learning gains, and the average learning gains increase with more hours of instruction” (p. 61). Statistical analyses demonstrated that hours of instruction are positively related to the probability of obtaining a high school credential as well.

In their study of reading instruction for low-level adult learners over a one program-year period, Alamprese et al. (2003), used multiple measures of attendance, including average hours that students attended reading classes, the number of weeks students attended class, and the percent of the total hours of class that students attended. Students averaged 124 hours of instruction over a period of 15 to 37 weeks. On average, the authors report that students attended $63 \%$ of the class hours available to them. While the study did not find a clear connection between hours of instruction and reading gains, results did show differences between learners who had attended class for more than seven weeks compared to those who had attended up to seven weeks. Patterns differed for nonnative and native-born students. 
The patterns of participation of students in adult literacy programs make some types of research difficult. However, several researchers have found ways to lessen the sample attrition and variations in time-on-task. Study design must allocate sufficient resources to sample retention and time-on-task must be carefully recorded so that it can be taken into account during analysis.

\section{Inaccurate Data}

One way to lower the cost of data collection is to draw from sources of data collected by programs for administrative, accountability, or planning purposes. However, Beder (1999) found that, in adult literacy programs, this data is often incomplete. He found that program data had many problems including, "inaccurate learner records, failure to preand posttest at specified intervals, administration of inappropriate levels of tests, failure to test, high attrition of subjects between pre and post data collection, programs' withdrawal from the study before program data collection was complete, and failure to forward data to researchers in a timely fashion” (p. 116).

Beder suggests that inaccurate data is caused by the lack of program staff trained in testing and data collection. In addition, he suggests that some program staff fear that testing and data collection may alienate learners who have a history of failure with tests when they were in the $\mathrm{K}-12$ system or have reasons to keep some personal data secret. In addition, the high dropout rate and inconsistent attendance make keeping complete records difficult.

Researchers sometimes overcome this problem by collecting their own data, but this adds to the expense of a study. In addition, since any data collection in the adult literacy environment is difficult, researchers should perform an extensive review of the data they collect to ensure accuracy of data collection and results. One approach to address this problem could be to verify the program data by collecting a sample of the same data that the program is collecting to check for accuracy. However, no example of this approach was found in the published literature.

Even when the study collects its own data, researchers should check for accurate data collection and reporting. The Adult Reading Components Study (ARCS) administered reading components tests to almost 1,000 adults in ESOL and ABE programs. In the ARCS study, researchers reviewed audio tapes of subject interviews, as well as test administration and results, including teachers' assessment of students' grade level equivalents. While time consuming, this process allowed the researchers to assess both the quality of the interviewing staff and the validity of results obtained in testing (R. Davidson, personal communication, May 31, 2006; Strucker, Davidson, \& Hilferty, 2000). 
Another approach to the problem of inaccurate data is to provide training to program staff and support to the development of efficient data entry systems to improve program data. For example, the Literacy in Libraries across America Initiative (Comings et al., 2003; Porter et al., 2005) faced the challenge of combining data across multiple programs, when data were collected differently and at different times by each program. The initiative aimed at increasing student persistence in 15 library literacy programs around the country. Researchers found that the operational meaning of terms including “active," "program entry,” and “program exit” differed across programs, depending on each program’s interpretation of the term.

In some programs, students were considered "active” if they attended activities in a given period. In other programs, however, students were considered "active” if they had not communicated that they had dropped out or if they maintained communication with the program without actually participating in activities. In order to develop a common measure across programs, researchers developed a definition that would work across multiple programs. A student was defined as active "in any given month if she or he had at least one hour of participation recorded in the database for that month" (Porter et al., 2005, p. 68). Activities could include any activity for which attendance was recorded and generally included some combination of tutoring, class, or group sessions, as well as computer lab activities.

Similar challenges arose for defining program entry. Some programs did not record a start date for students, while others recorded the date of first contact or the date of the first class or tutoring session. Researchers needed a common definition for first month of entry, which they decided on as the "first month in the database in which a student was 'active' after a period of three or more months of not being active” (Porter et al., 2005, pp. 68-69). "Program exit” was defined by a pattern of student participation, rather than a particular date. As such, the month of exit was defined as "the first month following program entry before at least three months of no activity” (Porter et al., 2005, p. 69). Once these definitions were set, the researchers trained the program staff to accurately input data, but in some cases this required new hardware and software supplied by the study. In this case, the added expense of training and support was essential for accurate data collection.

Despite efforts to create these common definitions, the data had several limitations. For example, in some instances, the month of program entry may not actually have been a student's first month in the program, since some students may have been active in the program several months earlier. With respect to program exit, the study's definition may not have captured exits without a return, and instead captured the end of the current spell of participation. Consequently, the study report notes that "exit rates may slightly underestimate the actual percentage of students who actually left a program" (Porter et al., 2005, p. 69). 
Since Beder's review of previous studies in 1999, programs have improved their data collection as part of the accountability demands of WIA. However, this data often needs cleaning and preparation before it is useful for analysis, according to one of the reviewers of an earlier draft of this paper. Some programs probably now have data collection systems sufficient for research, though some may not. Choosing programs that already have good data collection systems, being clear as to definitions of the data being collected, providing incentives, and then adding training and assistance to that system may be sufficient for most research studies. This approach would be less expensive than budgeting for all data collection for a study.

\section{Lack of Valid and Reliable Tests}

Beder (1999) identifies the lack of valid and reliable tests as a challenge to research in the adult literacy field. Research only works well when the expected outcomes of education are clearly defined. Without a clear definition of the outcomes and good instruments to measure those outcomes, the validity and reliability of a study's findings may be suspect.

Most of the instruments employed in the field were developed to guide instruction or measure outcomes for accountability systems, not to measure outcomes for research purposes. The existing tools may not measure the type of impact that is taking place or may not measure the small increments of improvement that occur over the limited time of treatment. The use of the same tests for research that are used for other program purposes may overestimate improvement since subjects become more familiar with the tests. This might not be a problem with experimental designs in which treatment and control groups are both developing familiarity with the tests. However, in some studies, such as longitudinal panel studies in which some subjects are in programs and some are not, test familiarity causes problems.

Researchers who conducted the What Works Study for Adult ESL Literacy Students concluded that the "assessments available for these students for instruction, research and accountability purposes range from non-existent to inadequate" (Condelli, 2002, p. 33). As part of their effort to capture literacy gains among low-level learners, researchers used a combination of standardized tests, including the Adult Language Assessment Scales (ALAS), the Comprehensive Adult Student Assessment System (CASAS) Functional Writing Assessment, and alternative assessments. The alternative assessments the team developed included a reading demonstration assessment, used to “measure students' ability to read and understand authentic materials they encounter in everyday life” (p. 33). Materials included food labels, flyers, simple stories, and newspaper articles. Researchers concluded that such an approach is promising and might serve as the basis for future development of more suitable assessments to measure changes in the reading development of low-literate ESOL students. 
As part of their study of persistence in library literacy programs in the U.S., Porter et al. (2005) included an assessment of literacy skill development for program participants over a 14-month period. Since no single test was available to measure the multiple aspects of literacy development-decoding, vocabulary, fluency, and reading comprehension - the study used a series of standardized assessments, which researchers felt were suitable for the study, and relied on different procedures for different students, thereby making the standardized assessments "more appropriate for each individual, and thus more meaningful and valid” (Porter et al., 2005, p. 58). These tests included the Test of Word Reading Efficiency (TOWRE), The Peabody Picture Vocabulary Test (PPVT), the reading comprehension portion of the Adult Basic Learning Examination (ABLE), and the Basic English Skills Test (BEST) administered only to English language learners in the study.

Similarly, in their study of reading instruction for low-level learners in adult literacy programs, Alamprese et al. (2003) employed multiple standardized reading tests to measure the development of reading skills among study participants. The six-part battery included the Woodcock-Johnson revised word attack and letter-word identification, WRAT3 word reading and word spelling segments, and the Nelson word meaning and reading comprehension segments.

In order to examine the literacy growth of adults over time, the Portland longitudinal study needed an assessment instrument to measure changes in basic skills over several years. The criteria for selecting such an instrument were that it be "(1) psychometrically sound; (2) available in multiple forms and appropriate for measuring skills growth over time in the target population; and (3) appropriate for and easy to administer in an in-home context” (NCSALL, 1998, p. 33). In addition, the instrument needed to be one not regularly used by adult literacy programs to avoid some adults having exposure to the test through participation in adult literacy programs, and the instrument needed to assess literacy proficiencies commensurate with those used in other large-scale assessment studies, such as the National Adult Literacy Survey.

Given these criteria, the research team chose the Test of Applied Literacy Skills (TALS) as the standardized basic skills test. To reduce the amount of time needed for administration of the assessment, researchers decided to use only the TALS document literacy scale, since this scale was highly correlated with the prose and quantitative scales of the test. Either Form A or B of the TALS was randomly assigned and administered in the five waves of data collection. Two other instruments were included in the assessment design of the Portland longitudinal study. The WordSum oral vocabulary assessment was used in the second wave of data collection, and a writing sample and the Test of Word Reading Efficiency (TOWRE) test of fluency and decoding skills were each added for the fifth wave of data collection. 
As part of ongoing national Birth Cohort Studies, the National Research and Development Centre (NDRC) in the U.K. added literacy assessments to recent waves of data collection. These assessments, designed or adapted for the study, include tests of reading and numeracy based on the national adult literacy curriculum, writing samples, and scales for people to examine learning differences, or learning disabilities (S. Reder, personal communication, June 8, 2006).

The examples described here reflect the need for the development of an approach to assessment that comprises a multiplicity of measures. For instance, literacy assessments are required that can assess both the components of reading (e.g., word recognition, decoding, vocabulary, and comprehension) and accomplishment of tasks with reading skills. One option is to identify a set of existing instruments suitable for research and support the development of additional instruments to provide a wider range of tools. Some of these tools would measure changes in skills and some would measure changes in ability to perform tasks. A commonly accepted set of assessment tools that were only used for research could overcome this challenge and make meta-analysis easier as well.

\section{Multiple Populations}

The adult literacy population is often treated as a homogeneous group, but, in fact, it is diverse in many ways that might affect research findings. A treatment that works for one group may not work for another, but a study might show an average effect across a population with wide diversity. Even when research is restricted to a specific population, important differences within the population may not be identified. For example, beginning ESOL students who are literate in their native language may respond differently from those who are not literate in their native language (Condelli, 2002). Unfortunately, individual ESOL classes may have students in both categories who are not identified as to their literacy skill background. Research that seeks a random sample of the entire population may not be relevant to one of the subpopulations. Studies could enlarge their sample size to include enough subjects from each subpopulation or could limit its sample to specific populations.

Research in K-12 schools must address the same challenge, but that research has well-defined subpopulations. Adult literacy researchers might also define subpopulations based on specific skill sets, and then suggest that researchers report findings based on these subpopulations. Some researchers have suggested such subpopulations.

Sabatini (1999) suggests four skill groups:

1. Truly nonliterate students who cannot read at all. They are rare in the U.S. 
2. Low literate students who do not read well. They probably dropped out of school or did not read and write enough while in school to develop strong literacy skills. They are probably the largest group of adults who could benefit from adult literacy services.

3. Reading disabled students who have trouble reading. They failed to develop strong literacy skills because of learning disabilities or cognitive disabilities. Though this group is probably between $5 \%$ and $10 \%$ of the adult population, they may make up a larger percentage of the group of adults who could benefit from adult literacy services.

4. Second language students who cannot read in English. They may be illiterate in their own language; they may be literate in a non-alphabetic language, or they may be literate in an alphabetic language but not speak English. This group may be less than $5 \%$ of the U.S. population, but they are at least $50 \%$ of the students in WIA-funded programs. (Strucker and Davidson (2003) found that among Spanish speakers in a sample drawn from WIA-funded programs [31\% of the sample], $80 \%$ had adequate or better than basic Spanish literacy skills.)

Strucker and Davidson (2003) identify ten clusters of adult students based on extensive testing of their English component reading skills. These clusters fall into three groups:

\section{$\underline{\text { GED and Pre-GED }}$}

1. Strong GED

2. Pre-GED with vocabulary and background information needs

3. Pre-GED with vocabulary, spelling, and fluency needs

$\underline{\text { Intermediate }}$

4. High intermediates with difficulties in print skills and fluency

5. Intermediates with stronger print than meaning skills

6. Intermediates with low fluency

7. Low intermediates

8. Low intermediates who have weak English language skills

Low Level and Beginning

9. Beginners

10. Reading and fluency impaired 
Comings (2003) identifies six populations of adult literacy program participants:

1. ESOL students who are literate in their native language and test at or below SPL4 ${ }^{3}$ on the BEST. ${ }^{4}$

2. ESOL students who are literate in their native language and test at or above SPL5.

3. GED ${ }^{5}$ students whose literacy skills are at or above the $8^{\text {th }}$ grade level as measured by a test such as the $\mathrm{TABE}^{6}$ or CASAS.

4. ABE students whose literacy skills are between the $6^{\text {th }}$ and $8^{\text {th }}$ grade level.

5. ABE students with literacy skills below the $6^{\text {th }}$ grade level.

6. ESOL students who are not literate in their native language.

Sometimes classes made up of a single skill group can be formed for small-scale research studies, but in most programs classes are mixed. In those cases, research analysis would have to separate out the data into subgroups, which might require a larger initial sample size.

\section{Lack of Program Resources}

Greenberg (2007) identifies the lack of program resources as a challenge to research in the adult literacy field. This is a challenge to research because it undermines successful implementation of interventions. This issue arises in $\mathrm{K}-12$ research as well, but the low level of funding provided to adult literacy programs exacerbates this situation. According to data from the Office of Vocational and Adult Education, the average annual expenditure per student in fiscal year 2002 was approximately $\$ 800$. The range, among the 50 states, was between $\$ 208$ and $\$ 2,683 ; 16$ states were below $\$ 500$, and only 9 states were above $\$ 1,000$ (U.S. Department of Education, 2005).

Because of low funding levels, most adult literacy programs lack the resources needed to participate in a research study. For example, they often do not have enough space to provide room for interviews or staff trained to administer tests. Greenberg (2007) offers an example of a teacher whose class was considered for participation in a study. Due to limited space, the teacher taught her classes in the same room that contained her office. Consequently, she was regularly interrupted with phone calls and other intrusions. The teacher kindly offered to allow the researcher to carry out the

\footnotetext{
${ }^{3}$ The BEST has 10 Student Performance Levels.

${ }^{4}$ The Basic English Skills Test is published by the Center for Applied Linguistics in Washington, D.C.

${ }^{5}$ The General Educational Development test provides certification of skills and knowledge that approximates those of a high school graduate.

${ }^{6}$ The Test of Adult Basic Education is published by McGraw-Hill in New York, NY.

${ }^{7}$ The Comprehensive Adult Student Assessment System is published by CASAS in San Diego, CA.
} 
desired intervention with a class within this room, but the researcher had to decline the offer, deeming the space inappropriate for research.

Another resource-related challenge to conducting research is that turnover among staff is high in programs that cannot provide stable employment. In addition, since funding is sometimes unstable, programs can disappear in the middle of a research project or decide that they can no longer afford to participate. A study by Purcell-Gates, Degener, Jacobson and Soler (2000) reflects this challenge. The study, which investigated the relationships between two dimensions of adult literacy instruction and change in the literacy practices of adult literacy students, involved data collection from 83 adult literacy classes in 22 states. Management of these multiple sites proved challenging to the research team. In some cases, programs closed before data could be collected. In one instance, a program "closed and reopened under new directorships three different times before a data collector could ever gain access to the site” (p. 24).

One solution is to provide additional resources to programs that participate in research projects. This, of course, causes an increase in research costs, especially since control or comparison groups might need access to a similar level of new resources. Significant differences in access to resources might result in important differences in the nature of treatment and control groups, which would, therefore, make it impossible to rule out rival explanations for the relationships observed in a study (Light, Singer, \& Willett, 1990). Research reports would have to identify the greater resources as an element of the intervention and explain that, without these additional resources, programs may not be successful in following advice based on evidence from the study.

\section{Sampling}

Because of a lack of resources, most adult literacy studies employ a convenience sample, but a probability sample provides a much stronger basis for analysis. Even when sufficient funding is available, defining a sample may be difficult. The first step in defining a sample usually involves obtaining a list of programs and within programs a list of teachers or students. Unfortunately, these lists sometimes do not exist or may be inaccurate or misleading. In some cases this situation is caused by inadequate data systems or untrained personnel. Even when the data systems are sufficient, they may be difficult to interpret. For example, programs, teachers, and students sometimes are defined by the funding that supports them, and this can lead to double (or more) counting of the same program or person, because they are funded by more than one source, or the mislabeling of them, since they are funded by a source that supports services different from those being offered.

Researchers use an array of tactics to create feasible and meaningful research samples. In a recent study, Waterman (2006) randomly selected adult ESOL classes to 
form treatment and control groups in her study of the effectiveness of an intervention to promote parent involvement and improve ESOL skills. To arrive at these groups, the researcher used multiple selection criteria. Within one school district, she sampled elementary schools with at least $50 \%$ of the students having immigrant parents and more than $85 \%$ of students with low socioeconomic status. In addition, she limited selection to schools whose principals expressed interest in supporting and receiving the intervention and agreed to provide a staff member to act as a liaison among the school, the ESOL teacher, the parents attending class, and the researcher.

These steps ensured equal support for adult ESOL classes in both treatment and control groups. With a group of schools that met these criteria, Waterman then randomly selected a single ESOL class from each of four different schools to be the treatment group and performed a similar process for selecting the control group. Classes in the treatment group received the intervention while those in the control group did not. Waterman limited her final analysis to women of Mexican origin who had at least one child in the participating school, which resulted in a sample size of 66 . The study findings, therefore, might have been different with ESOL students who were not Mexican mothers who had children in schools with less accommodating principals.

To provide for the equivalence of the treatment and control groups, Waterman made an effort to ensure the average equivalency between the groups of mothers included in the study, as well as the adult ESOL instructors involved in the study. This equivalence was determined using data on students' socioeconomic status, date of arrival in the U.S., level of formal education, hours of attendance in the ESOL class under study, and prior experience in ESOL instruction. For teachers, she looked at formal training related to adult education and ESOL teaching, prior experience teaching adult ESOL, and prior experience with parent involvement and immigrant parents.

Sampling procedures used in the Adult Reading Components Study (ARCS) provide another example of how the challenges of selecting a sample of study participants from adult literacy classes can be managed (Strucker et al., 2000). The study was the first large-scale attempt to describe the reading of students enrolled in ABE, ASE, and ESOL classes. It used a battery of individually administered reading and language tests. In order to select program sites, the research team first focused on obtaining the agreement of eight state directors to support the research process. The team next obtained lists of programs offering ABE, ESOL, or ASE services within each of these states. From that list, the researchers focused on programs serving at least 100 students, for reasons of economy. A sampling statistician used information on the proportion of ABE and ASE to ESOL classes and the native languages spoken by the ESOL students to select from state lists programs that accurately represented the mix of students within each state. The study director personally contacted all program directors to explain the study, and, ultimately, $80 \%$ of those programs contacted agreed to participate. These conversations provided important insights into the nature of the 
programs and the actual number of students at each program, which often differed from state-level figures. Without this firsthand information, the sample might have been different than originally projected.

Next, researchers faced the task of selecting individual students for inclusion in the study. Originally, this process required program directors to provide a list of all students in each school (with the exception of non-Spanish-speaking ESOL students, who were not included in the study). The team's sampling statistician would then randomly select 30-50 names for each center, depending on the center's size.

Researchers then set out to administer tests to those students selected. The realities of conducting research in adult programs quickly confronted researchers. Researchers would arrive at a learning center ready to test those selected students, only to find that most of these individuals were absent that day, had changed classes, or had dropped out in the two weeks between selection and testing. As a result, far fewer students than planned were tested, and resources were wasted on testers who had no students to test.

To overcome this problem, the research team changed its approach to sampling by selecting participants from among students actually present on the day of testing through a lottery. The number chosen by raffle varied to help ensure that subjects would be sampled in proportion to their numbers. So, for example, from a class of 20 students, the team would select two lottery "winners," while from a class of 10 students, only one "winner" would be chosen. Teachers were instructed to announce the testing to their classes one or two days prior to the testing only by indicating that some researchers would be coming to talk about some tests they were giving, that participation was voluntary, and that students would be paid for their involvement. This description was neutral in tone so that students could decide for themselves whether or not to participate.

Based on this experience, the research team offered five key recommendations for future studies in adult literacy. First, the students should be paid for their participation. Second, students should be tested during their scheduled class hours, using some form of on-the-spot lottery. Third, teachers or administrators should neither select nor influence the selection of students or classes that are sampled. Fourth, researchers should always meet personally with teachers and administrators to explain the study in detail before beginning data collection. Finally, "principal investigators should make themselves personally available to teachers, administrators and students” (Strucker et al., 2000, p. 29).

As data collection improves under WIA, lists of programs and lists of teachers and students within programs should become more available and more accurate. Even so, given the nature of adult participation in programs, final sample selection may have to take place at the program level, and so studies should plan for this added time and expense. 


\section{Shortcomings of Existing Data Sets}

One way to avoid the time and cost of collecting data is to employ data sets already built by other studies. While these data sets provide rich sources of data on which to conduct research (and are, in fact, cited as such in the section on advantages), they are often lacking in key variables of interest to researchers in adult education.

For example, in her study of the labor market performance of Spanish-speaking dropouts who obtained a Spanish GED, Soricone (2003) used a unique data set that combined GED testing data with Unemployment Insurance administrative records. While these data sets permitted a longitudinal analysis of earnings related to skill levels, neither set contained variables, such as immigrant status, age at immigration, location of previous schooling, or measures of English proficiency, which would have been useful in interpreting study findings, as well as in answering additional research questions. Such measures have been identified by other researchers (Wrigley, Richer, Martinson, Kubo, \& Strawn, 2003) as important to developing our understanding of the activities and outcomes of limited English-proficient adults in the U.S.

An additional challenge is that administrative records of the Unemployment Insurance system have an inherent limitation in what they can tell us about earnings. Periods of "zero earnings" could in fact reflect unemployment, employment in an underground economy, self-employment, incarceration, departure from a state or the U.S., and even death. Thus, the true nature of immigrant earnings may be misrepresented with the use of such data. At this point, better sources of earnings data are not available.

The National Household Education Survey (NHES) provides valuable insight into adults' participation in adult education as well as earnings. One drawback to this data set, however, is that the information is self-reported and may, therefore, overestimate actual earnings (Hollenbeck, 1996; Uvin, 2001). Furthermore, the NHES does not include adults who live in households without telephones, institutionalized adults, and adults in the armed forces. Consequently, certain ethnic, racial, or linguistic groups may be underrepresented. Another problem with these data is that they do not include important information on workers, such as age at immigration for immigrants, and firm size, which would allow researchers to more appropriately attribute some of the variation in workers' earnings (Uvin, 2003). With respect to the information on participation in adult education that NHES can provide, these data lack measures of, for example, the supply of available ESOL classes, as well as indicators of individuals' status on waitlists (Uvin, 2001).

Other national data sets have limitations that impact the nature of research that can be undertaken using them. For example, the sample from the High School and Beyond (HS\&B) data set used by Murnane et al. (1999) includes individuals who began the study in $10^{\text {th }}$ grade. Consequently, while the data set provides a rich source of 
longitudinal data, it excludes individuals who may have dropped out prior to $9^{\text {th }}$ grade, a population that is likely to be represented in adult literacy programs.

Nothing can be done about missing variables in data sets that already exist. Adult literacy researchers, though, could identify the data elements they need and promote their inclusion in future studies.

\section{Lack of Research Resources}

Just as the adult literacy field lacks resources to support and improve programs, it lacks resources to fund research. Direct funding for research in adult literacy probably amounts to less than \$10 million a year. Research funding available from the Institute of Education Sciences and the National Institute for Child Health and Human Development is mostly focused on $\mathrm{K}-12$ children. Most foundations that support education research are also focused on $\mathrm{K}-12$ children. Some government agencies that address such issues as workforce development or welfare include adult literacy in their research funding but usually as a component of a larger program effort. For example, the National Evaluation of Welfare-to-Work Strategies was designed to offer insight into the effectiveness of different types of welfare-to-work programs. While the study provided information on the economic and other outcomes of program participants, it also offered suggestions for improving program design for educational programs that work with welfare recipients (Hamilton, 2002).

This lack of funding discourages some academics from dedicating all or part of their career to adult literacy. This makes it difficult for potential graduate students to find a mentor who could help them develop an academic career. These constraints have limited the establishment of peer-reviewed journals and other publication opportunities. This cycle of constraints has produced a limited scholarly community.

That limited community has made attempts to develop itself. The Adult Education and Adult Literacy Special Interest Group (SIG) within the American Educational Research Association has grown from less than 30 to almost 200 members over the last six years. The SIG offers a venue in which a scholarly community can be built. Adult literacy SIGs have also been established in the International Reading Association and the National Reading Conference.

The National Institute for Literacy (NIFL) is developing a comprehensive agenda for research and development in adult literacy, and though it cannot fund a large research effort, its leadership could expand resources for the field. Collaboration among NIFL, IES, NICHD, and the AERA SIG, therefore, may be one way to work toward expanded resources for research. This could lead to a larger scholarly community, which could then 
support peer-reviewed journals. With a stronger research community and a clear agenda, funding might increase. 


\section{OPTIONS FOR SUPPORTING RIGOROUS RESEARCH}

Individual researchers could address these challenges on their own. However, the dialogue among the advisory group identified options for the adult literacy field to work together to support rigorous research. These options include: (1) a more ambitious effort to describe and develop approaches to overcoming the challenges to scientific research in this field, (2) larger studies, and (3) promotion of adult literacy programs as allies in research.

\section{A More Ambitious Effort}

The group of advisors suggested that this monograph could only begin a dialogue, not solve the problems of challenges to rigorous research in this field. They suggested that a more ambitious effort could produce a detailed approach to implementation of rigorous research in the adult literacy field. If the leadership of the field-funding agency staff, researchers, and practitioners - undertook a more ambitious effort, they might lay the foundation for a system of research that supports improvement of program services.

This collaboration might begin its efforts with the description of theory and the models that could derive from it. This effort could build a consensus about models for services. Once those models were established, the research community could pursue a research agenda that would test and improve these models as well as explore new models that might prove to be more effective.

An ambitious effort might both identify more challenges and provide resources for scholars to expand the sections on each challenge examined in this monograph. This would require more resources than were available for this monograph, but that investment might set the stage for more efficient use of the limited research funds that are available.

\section{Larger Studies}

Since the challenges to scientific research that the adult literacy field faces require resources to overcome, researchers might consider pooling their resources in studies that answer several questions with the same data collection procedure. This would allow more resources to be put into design and implementation of data collection, which would then allow studies to address the many challenges to rigorous research in this field. One large study that answers five questions might be more likely to succeed than five smaller individual studies.

The economies of scale that larger multi-question projects would provide might also increase the efficiency of the use of funds available for research. Several funding 
agencies might work together to pool resources and derive more research, and research of a higher quality, than they could manage on their own. Such collaboration is taking place in a program of research that includes six studies focused on adult literacy that are funded and managed by NIFL, NICHD, and OVAE. In addition, agencies that fund K-12 research might include cohorts of adults in their studies. Adding a cohort of adults to a well-designed study might be less expensive than a separate adult study.

\section{Programs as Allies in Research}

Since most research in the field takes place in adult literacy programs, practitioners could be allies in lowering the challenges to research. At this time, the research and practice communities only engage in discourse occasionally. The advisory group suggested several ways in which the research community could deepen its contacts with programs.

The advisors suggested that most practitioners probably need training to become better consumers of research, but the advisors suggested that this training should strive to help practitioners see themselves as active partners in the process of connecting research and practice. Practitioners should be encouraged to participate in research studies. This encouragement could explain why research is important, how it is not evaluation of program efforts, and what changes the programs might have to make to be supportive of research. This might also lead to more programs willing and able to be good research sites. Practitioners should also be encouraged to adapt research findings to their specific contexts and feed questions and hypotheses from their classrooms to the research community. 


\section{NEXT STEPS}

This monograph is a small step in a larger effort to improve scientific research in the adult literacy field and to encourage more research as well. This step should be followed by a dialogue among scholars in the field that expands the insights recorded here. If that dialogue is sustained, the field should be able, through trial and error and through building on previous experience, to address these challenges in ways that are within the limits of the resources available. 



\section{REFERENCES}

Alamprese, J., Tao, F., \& Price, C. (2003). Study of reading instruction for low-level learners in adult basic education programs: Volume 1: Study findings (Draft Report). Bethesda, MD: Abt Associates, Inc.

American Psychological Association. (1992). Ethical principles of psychologists and code of conduct. American Psychologist, 47, 1596-1611. Retrieved December 6, 2006, from: http://www.apa.org/ethics/code1992.html\#Principle\%20D

Beder, H. (1999). The outcomes and impacts of adult literacy education in the United States (NCSALL Report No. 6). Cambridge, MA: National Center for the Study of Adult Learning and Literacy.

Beder, H. \& Medina, P. (2001). Classroom dynamics in adult literacy education (NCSALL Report No. 18). Cambridge, MA: National Center for the Study of Adult Learning and Literacy.

Behrman, J., \& Stacey, N. (Eds.). (1997). The social benefits of education. Ann Arbor, MI: University of Michigan Press.

Bingman, M. B., Ebert, O., \& Smith, M. (1999). Changes in learners' lives one year after enrollment in literacy programs: An analysis from the Longitudinal Study of Adult Literacy Participants in Tennessee (NCSALL Report No. 11). Cambridge, MA: National Center for the Study of Adult Learning and Literacy.

Brooks, G., Torgerson, C. J., \& Porthouse, J. (2003). A systematic review and metaanalysis of randomized controlled trials evaluating interventions in adult literacy and numeracy. Journal of Research in Reading, 26(3), 234-255.

Comings, J. (2003). Building an evidence-based adult education system (NCSALL Occasional Paper). Cambridge, MA: National Center for the Study of Adult Learning and Literacy.

Comings, J., Cuban, S., Bos, J. M., \& Porter, K. E. (2003). “As long as it takes:” Responding to the challenges of adult student persistence in library literacy programs. New York: MDRC.

Comings, J., Parrella, A., \& Soricone, L. (1999). Persistence among adult basic education students in pre-GED classes (NCSALL Report No. 12). Cambridge, MA: National Center for the Study of Adult Learning and Literacy. 
Comings, J., Reder, S., \& Sum, A. (2001). Building a level playing field (NCSALL Occasional Paper). Cambridge, MA: National Center for the Study of Adult Learning and Literacy.

Comings, J., Soricone, L., \& Santos, M. (2006). An evidence-based adult education program model appropriate for research (NCSALL Occasional Paper).

Cambridge, MA: National Center for the Study of Adult Learning and Literacy.

Comings, J., Sum, A., \& Uvin, J. (2000). New skills for a new economy: Adult education's key role in sustaining economic growth and expanding opportunity. Boston, MA: MassINC.

Condelli, L. (2002). Effective instruction for adult ESL literacy students: Findings from the What Works Study. Washington, DC: American Institutes for Research.

Curtis, M. E. (1980). Development of the components of reading. Journal of Educational Psychology, 72, 656-669.

Curtis, M. E. (1997). Teaching reading to children, adolescents, and adults: Similarities and differences. In L.R. Putnam, (Ed.), Readings on language and literacy: Essays in honor of Jeanne Chall (pp. 75-88). Cambridge, MA: Brookline Books.

Curtis, M. E. (2006). The role of vocabulary instruction in adult basic education. In J. Comings, B. Garner, \& C. Smith (Eds.), Review of adult learning and literacy, Vol. 6 (pp. 43-69). Mahwah, NJ: Lawrence Erlbaum Associates.

Green, J. G., Duncan, R. E., Barnes, G. L., \& Oberklaid, F. (2003). Putting the 'informed' into 'consent': A matter of plain language. Journal of Paediatrics and Child Health, 39(9), 700-703.

Greenberg, D. (2007). Tales from the field: The struggles and challenges of conducting ethical and quality research in the field of adult literacy. In A. Belzer \& H. Beder (Eds.), Toward defining and improving quality in adult basic education (pp. 125-140). Hillside, New Jersey: Lawrence Erlbaum Associates.

Greenberg, D., Ehri, L., \& Perin, D. (1997). Are word-reading processes the same or different in adult literacy students and third-fifth graders matched for reading level? Journal of Educational Psychology, 89, 262-275. 
Greenberg, D., Ehri, L., \& Perin, D. (2002). Do adult literacy students make the same word-reading and spelling errors as children matched for word-reading age? Scientific Studies of Reading, 6(3), 221-243.

Hamilton, G. (2002). Moving people from welfare to work: Lessons from the national evaluation of welfare-to-work strategies. New York: MDRC. Retrieved May 26, 2006, from http://www.mdrc.org/project_21_11.html

Hollenbeck, K. (1996, April). A framework for assessing the economic benefits and costs of workplace literacy training. Paper presented at Workplace Learning: The Strategic Advantage Conference, Milwaukee, Wisconsin.

Kerckhoff, C., Raudenbush, S. W., \& Glennie, E. (2001). Education, cognitive skill, and labor force outcomes. Sociology of Education, 74, 1-24.

Kruidenier, J. (2002). Research-based principles for adult basic education reading instruction. Washington, DC: National Institute for Literacy. Retrieved May 26, 2006, from: http://www.nifl.gov/partnershipforreading/publications/adult.html

Light, R. J., Singer, J. D., \& Willett, J. B. (1990). By design: Planning research on higher education. Cambridge, MA: Harvard University Press.

Merriam, S. B. (2004). The changing landscape of adult learning theory. In J. Comings, B. Garner, \& C. Smith (Eds.), Review of adult learning and literacy, Vol. 4 (pp. 199-220). Mahwah, NJ: Lawrence Elrbaum Associates.

Murnane, R. J., Willett, J. B., \& Boudett, K. P. (1995). Do high school dropouts benefit from obtaining a GED? Educational Evaluation and Policy Analysis, 17(2), 133-147.

Murnane, R. J., Willett, J. B., \& Boudett, K. P. (1997). Does a GED lead to more training, post-secondary education, and military service for school dropouts? Industrial and Labor Relations Review, 51(1), 100-116.

Murnane, R. J., Willett, J. B., \& Tyler J. H. (1999). Who benefits from obtaining a GED? Evidence from High School and Beyond (Working Paper 7172). Cambridge, MA: National Bureau of Economic Research.

National Center for the Study of Adult Learning and Literacy. (1998). Performance Report May 1, 1998-October, 1998. Cambridge, MA: Author. 
Porter, K. E., Cuban, S., \& Comings, J. (2005). “One day I will make it:” A study of adult student persistence in library literacy programs. New York: MDRC.

Purcell-Gates, V., Degener, S., Jacobson, E., \& Soler, M. (2000). Affecting change in literacy practices of adult learners (NCSALL Report No. 17). Cambridge, MA: National Center for the Study of Adult Learning and Literacy.

Raich, P. C., Plomer, K. D., \& Coyne, C. A. (2001). Literacy, comprehension, and informed consent in clinical research. Cancer Investigation, 19(4), 437-445.

Read, C. (1988). Adults who read like children: The psycholinguistic bases. Report to the U.S. Department of Education. Madison, WI: Wisconsin Center for Education Research, University of Wisconsin-Madison.

Reder, S. (2005). The “Lab School.” Focus on Basics, 8(A), 1, 3-7.

Reder, S. (2006, April). The development of literacy proficiency and literacy practices. Paper presented at the Annual Meeting of the American Educational Research Association, San Francisco, CA.

Reder, S. (in press). Dropping out and moving on: Life, literacy and development among school dropouts. Cambridge, MA: Harvard University Press.

Ross, J. G., Sundberg, E. C., \& Flint, K. H. (1999). Informed consent in school health research: Why, how, and making it easy. Journal of School Health, 6(5), 171-176.

Rudd, R. E., Moeykens, B. A., \& Colton, T. C. (2000). Health and literacy: A review of medical and public health literature. In J. Comings, B. Garner, \& C. Smith (Eds.), Annual review of adult learning and literacy, Vol. 1 (pp. 158-199). San Francisco: Jossey-Bass.

Sabatini, J. (1999). Adult reading acquisition. In A. Wagner, R. Venezky, \& B. Street, (Eds.), Literacy: An international handbook (pp. 49-53). Boulder, CO: Westview Press.

San Antonio, D. M. (2001). Adolescent lives in transition: Social class influences on the adjustment to middle school. Unpublished doctoral dissertation, Harvard Graduate School of Education. 
Sawyer, D. J., \& Joyce, M. T. (2006). Research in spelling: Implications for adult basic education. In J. Comings, B. Garner, \& C. Smith (Eds.), Review of adult learning and literacy, Vol. 6 (pp. 71-112). Mahwah, NJ: Lawrence Erlbaum Associates.

Silver-Pacuilla, H. (in press). Assistive technology and adult literacy. In J. Comings, B. Garner, \& C. Smith (Eds.), Review of adult learning and literacy, Vol. 7. Mahwah, NJ: Lawrence Erlbaum Associates

Smith, C., Hofer, J., Gillespie, M., Solomon, M., \& Rowe, K. (2003). How teachers change: A study of professional development in adult education (NCSALL Report No. 25). Cambridge, MA: National Center for the Study of Adult Learning and Literacy.

Soricone, L. (2000). When are dropouts most likely to get a GED? Evidence from the National Education Longitudinal Study. Unpublished qualifying paper, Harvard Graduate School of Education.

Soricone, L. (2003). Do cognitive skills affect the labor market outcomes of Spanishspeaking dropouts? Unpublished doctoral dissertation, Harvard Graduate School of Education.

Stanovich, K. (1986). Matthew effects in reading: Some consequences of individual differences in the acquisition of literacy. Reading Research Quarterly, 21, 360-406.

Strucker, J., Curtis, M. \& Adams, M. (in press). Results of the mid-level reader study. Cambridge, MA: National Center for the Study of Adult Learning and Literacy.

Strucker, J., \& Davidson, R. (2003). Adult reading components study (ARCS) (NCSALL Research Brief). Cambridge, MA: National Center for the Study of Adult Learning and Literacy.

Strucker, J., Davidson, R., \& Hilferty, A. (2000). How the ARCS was done (NCSALL Occasional Paper). Cambridge, MA: National Center for the Study of Adult Learning and Literacy.

Tyler, J. H. (2002). Basic skills and the earnings of dropouts. Brown University Department of Economics (Working Paper No. 2002-09). Retrieved May 5, 2006, from: http://www.brown.edu/Departments/Education/personnel.php?who=jhtyler\#pubs 
Tyler, J. H. (2004). Does the GED improve earnings? Estimates from a sample of both successful and unsuccessful GED candidates. Industrial and Labor Relations Review, 57(4), 579-98.

Tyler, J. H. (2005). The General Educational Development (GED) credential: History, current research, and directions for policy and practice. In J. Comings, B. Garner, \& C. Smith (Eds.), Review of adult learning and literacy, Vol. 5 (pp. 45-84). Mahwah, NJ: Lawrence Erlbaum Associates.

Tyler, J. H., \& Kling, J. (2004). Prison-based education and re-entry into the mainstream labor market. Brown Department of Economics (Working Paper 2004-10). Retrieved May 26, 2006 from: http://www.brown.edu/Departments/Education/personnel.php?who=jhtyler

Tyler, J. H., Murnane, R. J., \& Willett, J. B. (1998). Estimating the impact of the GED on the earnings of young dropouts using a series of natural experiments (Working Paper 6391). Cambridge, MA: National Bureau of Economic Research.

Tyler, J. H., Murnane, R. J., \& Willett, J. B. (2000). Do the cognitive skills of dropouts matter in the labor market? Journal of Human Resources, 35(4), 748-754.

Tyler, J. H., Murnane, R. J., \& Willett, J. B. (2003). Who benefits from a GED? Evidence for females from high school and beyond. Economics of Education Review, 22(3), 237-247.

Tyler, J. H., Murnane, R. J., \& Willett, J. B. (2004). The devil's in the details: Evidence from the GED on the large effects of small differences in high stakes exams. Economics of Education Review, 23(4), 336-49.

U.S. Department of Education. (2005). Adult Education and Family Literacy Act: program facts. Washington, D.C.: U.S. Department of Education, Office of Vocational and Adult Education. Retrieved June 20, 2006, from: http://www.ed.gov/about/offices/list/ovae/pi/AdultEd/aeflaprogfacts.doc

U.S. Department of Education. (2006). Adult Education and Family Literacy Act program year 2003-2004. Report to Congress on state performance. Washington, DC: Author.

Uvin, J. E. (2001). Who participates in adult English for speakers of other languages courses? Unpublished qualifying paper, Harvard Graduate School of Education. 
Uvin, J. E. (2003). Estimating the effects of job loss and training on the earnings trajectories of limited English proficient workers. Unpublished doctoral dissertation, Harvard Graduate School of Education.

Waterman, R. (2006). The value of Mexican mothers, the power of effective adult education: Fueling viable parent involvement through school-based ESL classes. Unpublished doctoral dissertation, Harvard Graduate School of Education.

Wrigley, H. S., Richer, E., Martinson, K., Kubo, H., \& Strawn, C. (2003). The language of opportunity: Expanding employment prospects for adults with limited English skills. Washington, DC: Center for Law and Social Policy.

Young, M., Fleischman, H., Fitzgerald, N., \& Morgan, S. (1994). National evaluation of adult education programs: Fourth report: Learner outcomes and program results. Arlington, VA: Development Associates.

Young, M., Fleischman, H., Fitzgerald, N., \& Morgan, S. (1995). National evaluation of adult education programs: Executive summary. Arlington, VA: Development Associates. 



\section{APPENDIX}

\section{Advisors}

Judy Alamprese, Abt Associates

Hal Beder, Rutgers University*

Mary Beth Curtis, Leslie University

Daphne Greenberg, Georgia State University*

John Kruidenier, Consultant

Steve Reder, Portland State University

John Sabitini, Educational Testing Service

Cristine Smith, University of Massachusetts at Amherst

John Strucker, Harvard Graduate School of Education

*Did not attend meeting

\section{Peer Reviewers}

Larry Condelli, American Institutes for Research

John Tyler, Brown University

\section{Government Officials}

Brett Miller, Institute of Education Sciences

Lynn Reddy, National Institute for Literacy

Anne Sweet, Institute of Education Sciences 



\section{NCSALL}

National Center for the Study of Adult Learning and Literacy

\section{NCSALL’s Mission}

NCSALL's purpose is to improve practice in educational programs that serve adults with limited literacy and English language skills, and those without a high school diploma. NCSALL is meeting this purpose through basic and applied research, dissemination of research findings, and leadership within the field of adult learning and literacy.

NCSALL is a collaborative effort between the Harvard Graduate School of Education, World Education, The Center for Literacy Studies at The University of Tennessee, Rutgers University, and Portland State University. NCSALL is funded by the U.S. Department of Education through its Institute of Education Sciences (formerly Office of Educational Research and Improvement).

\section{NCSALL’s Research Projects}

The goal of NCSALL's research is to provide information that is used to improve practice in programs that offer adult basic education, English for speakers of other languages, and adult secondary education services. In pursuit of this goal, NCSALL has undertaken research projects in four areas: (1) learner persistence, (2) instructional practice and the teaching/learning interaction, (3) professional development, and (4) assessment.

\section{NCSALL’s Dissemination Initiative}

NCSALL's dissemination initiative focuses on ensuring that practitioners, administrators, policymakers, and scholars of adult education can access, understand, judge and use research findings. NCSALL publishes Focus on Basics, a quarterly magazine for practitioners; Focus on Policy, a twice-yearly magazine for policymakers; Review of Adult Learning and Literacy, a scholarly review of major issues, current research, and best practices; and NCSALL Reports and NCSALL Occasional Papers, periodic publications of research reports and articles. In addition, NCSALL sponsors the Connecting Practice, Policy, and Research Initiative, designed to help practitioners and policymakers apply findings from research in their instructional settings and programs.

For more about NCSALL or to download free copies of our publications, please visit our Web site at:

\section{www.ncsall.net}

